\title{
Functional differences in bi-level pressure preset ventilators
}

\author{
M.P. Highcock, J.M. Shneerson, I.E. Smith
}

\begin{abstract}
Functional differences in bi-level pressure preset ventilators. M.P. Highcock, J.M. Shneerson, I.E. Smith. (C) ERS Journals Ltd 2001.

ABSTRACT: The performance of four bilevel positive pressure preset ventilators was compared.

The ventilators tested were; BiPAP ST30 (Respironics); Nippy2 (B + D Electrical); Quantum PSV (Healthdyne); and Sullivan VPAP II ST (Resmed). A patient simulator was used to determine the sensitivity of the triggering mechanisms and the responses to a leak within the patient circuit, and to changes in patient effort.

Significant differences $(p<0.05)$ between the devices were seen in the trigger delay time and inspiratory trigger pressure. When a leak was introduced into the patient circuit, the fall in tidal volume $(V T)$ was less than ten per cent for each ventilator. The addition of patient effort produced a number of changes in the ventilation delivered. Patient efforts of $0.25 \mathrm{~s}$ induced a variable fall in $V \mathrm{~T}$. An increase in $V_{\mathrm{T}}$ was seen with some ventilators with patient efforts of $1 \mathrm{~s}$ but the effect was variable. Trigger failures and subsequent falls in minute volume were seen with the BiPAP and the Nippy 2 at the highest respiratory frequency.

Differences in the responses of the ventilators are demonstrated that may influence the selection of a ventilator, particularly in the treatment of breathless patients with ventilatory failure.
\end{abstract}

Eur Respir J 2001; 17: 268-273.
The Respiratory Support and Sleep Centre, Papworth Hospital, Papworth Everard, Cambridge, CB3 8RE, UK.

Correspondence: M.P. Highcock, The Respiratory Support and Sleep Centre, Papworth Hospital, Papworth Everard, Cambridge, CB3 8RE, UK Fax: 441480830620

Keywords: Bi-level pressure ventilators mechanical ventilators noninvasive positive pressure ventilators

ventilator performance

Received: February 212000

Accepted after revision September 6 2000
Noninvasive intermittent positive pressure ventilation (NIPPV) was first developed using volume preset devices with pressure triggering and no expiratory airway pressure [1, 2]. Bilevel pressure preset flow triggered devices are now increasingly used for NIPPV. The superiority of these devices is unproven [3, 4] yet there are several theoretical advantages over volume preset ventilators. Pressure preset ventilation enables compensation for leaks to occur, whilst volume preset does not [5]. Air leaks are common during NIPPV and may lead to inadequate treatment [6]. A pressure preset ventilator should respond to increased patient effort during a breath with increased flow and a greater tidal volume $(V \mathrm{~T})$ [7], in contrast to volume preset ventilators where $V \mathrm{~T}$ is fixed. The addition of expiratory positive airway pressure (EPAP) to the ventilator circuit may be useful in patients with dynamic hyperinflation, as it reduces the effort needed to trigger the ventilator $[8,9]$. Patients with ventilatory failure due to obstructive sleep apnoea may benefit from EPAP as it stabilises the airway in the same way as continuous positive airway pressure [10]. Flow triggering has been shown to reduce patient effort compared to pressure triggering whilst maintaining equivalent levels of ventilation [11].

Previous studies comparing the performance of ventilators using lung models have all shown differences between the devices tested [5, 12, 13], but there has been little emphasis on the effects that patient effort might have on the ventilators, although many of the presumed advantages of bilevel pressure preset ventilators relate to patient effort. This paper has examined the responses of four bilevel pressure preset ventilators to leaks within the circuit and changes in simulated patient effort.

\section{Methods}

\section{Ventilators tested}

Four brands of ventilator in current use for NIPPV were examined. All are bilevel positive pressure devices with individually adjustable inspiratory and expiratory positive airway pressures (IPAP and EPAP, respectively). All are triggered from EPAP to IPAP by changes in flow within the ventilator circuit.

BiPAP S/T 30 (Respironics Inc., Pittsburg, PA, $U S A)$. This device may be operated in spontaneous, timed, or spontaneous/timed $(\mathrm{S} / \mathrm{T})$ mode. In $\mathrm{S} / \mathrm{T}$ mode a minimum respiratory frequency $(f \mathrm{R})$ is preset, and timed breaths are delivered if the patient's $f \mathrm{R}$ falls below this. The inspiratory time (tI) and expiratory time $(t \mathrm{E})$ are not preselected, but are subsequently determined according to unquoted flow criteria.

Nippy2 (B+D Electrical Ltd., Stratford-upon-Avon, Warwickshire, $U K$ ). The ventilator operates only in $\mathrm{S} / \mathrm{T}$ mode. $t \mathrm{I}$ is preset and determines the transition from IPAP to EPAP. A maximum $t \mathrm{E}$ is also preset. The trigger sensitivity is adjustable between a quoted range of $4-80 \mathrm{~L} \cdot \mathrm{min}^{-1}$. 
Quantum Pressure Support Ventilator (Healthdyne technologies, Marietta, GA, USA). Spontaneous and $\mathrm{S} / \mathrm{T}$ modes are available. The rate of change of pressure during the transition from EPAP to IPAP may be altered by adjusting the rise time control. A range of $0.1-0.9 \mathrm{~s}$ is available. In $\mathrm{S} / \mathrm{T}$ mode a minimum $f \mathrm{R}$ is selected. The $t \mathrm{I}$ for timed breaths is determined by selecting a percentage $t \mathrm{I}$. However, if the breaths are patient triggered then the $t \mathrm{I}$ is determined by flow criteria. Cycling from IPAP to EPAP occurs when inspiratory flow falls to $75 \%$ of the peak value and the preset IPAP has been achieved.

Sullivan VPAP II ST (Resmed Ltd., Abingdon, Oxfordshire, UK). Spontaneous, timed and $\mathrm{S} / \mathrm{T}$ modes are available. The rise time is adjustable and a range of $0.3-0.9 \mathrm{~s}$ is offered. In $\mathrm{S} / \mathrm{T}$ mode a minimum $f \mathrm{R}$ is selected. Transitions between IPAP and EPAP are triggered by the patients breathing according to unquoted flow criteria, but a minimum and maximum $t \mathrm{I}$ are also preset.

\section{Experimental model}

A patient simulator which has previously been described [5] was used to make all measurements (fig. 1). It consists of a bellows type lung simulator (Ohmeda, Herts, UK) contained within a box, connected to a negative pressure pump (Negavent; Dima Italia, Milan, Italy). The elastance and the resistance of the lung simulator were set to $20 \mathrm{cmH}_{2} \mathrm{O} \cdot \mathrm{L}^{-1}$ and $5 \mathrm{cmH} \mathrm{O}_{2} \mathrm{O} \cdot \mathrm{L}^{-1} \cdot \mathrm{s}$ respectively. The ventilators were connected to the simulator using identical circuits, incorporating a Whisper swivel II expiatory valve (Respironics Inc.). A connector with a leak of radius $2 \mathrm{~mm}$, which can be opened or closed, and a pneumotachograph (PNT) (Si-Plan Electronics Research, Stratford-upon-Avon, UK) were placed between the expiratory valve and the lung simulator. The box was not airtight but had a leak sufficient to allow the expansion of the bellows, with no measurable rise in pressure within the box.

Pressure within the box and in the circuit, between the pneumotachograph and the lung simulator, was measured using calibrated pressure transducers (Vygon,

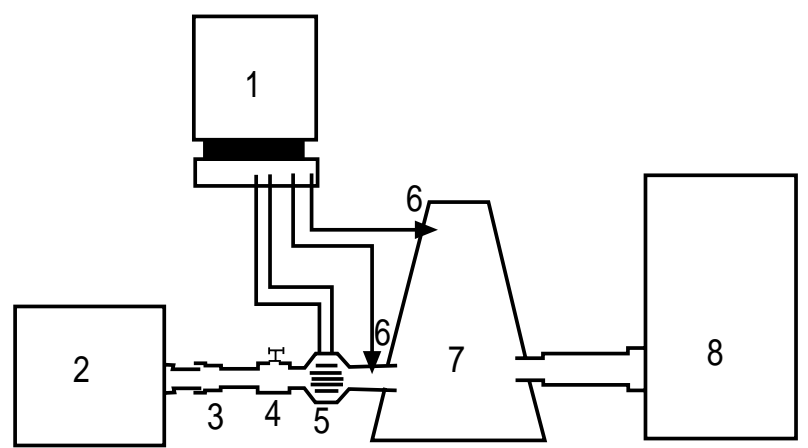

Fig. 1. - Experimental set up. 1: data logger; 2: bilevel ventilator; 3: expiratory valve; 4: variable leak; 5: pneumotachograph; 6: pressure transducer; 7: lung simulator within a box; 8: negative pressure pump.
Gloucestershire, UK). The inspiratory flow signal from the PNT was integrated to give a volume signal and was calibrated using a $1 \mathrm{~L}$ syringe (Vitalograph, Buckinghamshire, UK). All signals were sampled at $33 \mathrm{~Hz}$ and recorded digitally on a data-logging system (Cardas, Pilogic, Dyffed, UK).

The negative pressure pump generated pulses of negative pressure within the box to simulate patient effort, expand the bellows and trigger the ventilators. The software within the pump was modified to eliminate any interaction between the pump and the ventilators. A sensor within the hose of the negative pressure pump normally monitors pressure continuously. Following modification, this sensor operated initially ensuring that the correct preset pressure is delivered by the pump. However it was subsequently disabled, so that the pump continued to deliver identical "patient effort" irrespective of any changes in pressure created within the box by the action of the ventilator on the bellows. Thus the "patient effort" applied was consistent, irrespective of the action of the ventilator.

The ventilators were used in the $\mathrm{S} / \mathrm{T}$ mode with the minimum EPAP. The $f \mathrm{R}$ was set at twelve breaths $\mathrm{min}^{-1}$ with an inspiratory:expiratory ratio of $1: 2$. Where adjustable, inspiratory triggers were set at the most sensitive, and the fastest rise in inspiratory pressure was selected. When any variable was altered, ten breaths were allowed for equilibration and results quoted as means of the next twenty breaths.

\section{Experimental protocol}

Leak in the patient circuit. For each ventilator, the $V \mathrm{~T}$, IPAP and $t$ I were measured with the leak between the expiratory valve and the PNT closed and then open, over the range of preset pressures at intervals of $3-4 \mathrm{cmH}_{2} \mathrm{O}$.

Trigger sensitivity. The ventilators were set to deliver an IPAP of $20 \mathrm{cmH}_{2} \mathrm{O}$, with the other settings unchanged. The negative pressure pump was then set to deliver a pressure of $-8 \mathrm{cmH}_{2} \mathrm{O}$, to simulate patient breaths. "Patient breaths" were of $1 \mathrm{~s}$ duration and at a rate of 16 breaths $\cdot \mathrm{min}^{-1}$. The resulting ventilator breaths were then analysed and the trigger delay time and pressure required to initiate triggering were measured for each machine. The trigger delay time was defined as the time taken for the ventilator to increase airway pressure above baseline from the onset of inspiration. The onset of inspiration was taken as the initial fall in pressure measured within the box. The inspiratory trigger pressure was measured as the difference between the baseline airway pressure and the minimum airway pressure during the triggering of inspiration.

Changes in duration and frequency of patient effort. Without changing the ventilator settings, a baseline minute volume was measured over a 5 min period. The negative pressure pump was then set to deliver "patient breaths" of differing duration and frequency. Under each condition, the response of the 


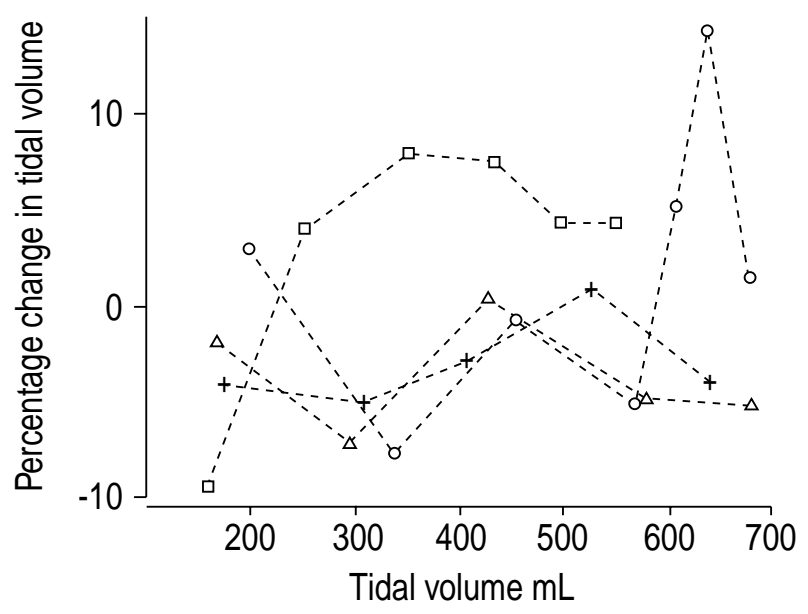

Fig. 2. - The effect on tidal volume when the leak was opened. $\bigcirc$ : BiPAP ST 30; $\triangle$ : Nippy2; + : Quantum PSV; $\square$ : VPAP II ST.

ventilator was assessed by measuring minute volume over a $5 \mathrm{~min}$ period and compared with baseline.

The pump delivered a pressure of $-8 \mathrm{cmH}_{2} \mathrm{O}$ to the box, at rates of 16,20 and 24 breaths $\cdot \min ^{-1}$ and for 0.25 and $1 \mathrm{~s}$ duration.

\section{Results}

\section{Leak in the patient circuit}

The percentage change in $V \mathrm{~T}$ and IPAP for each ventilator with the leak opened are illustrated in figs 2 and 3. All four machines compensated well for the leak. Any falls in $V \mathrm{~T}$ were less than $10 \%$ and falls in IPAP were less than $8 \%$.

The change in flow, created by the leak, delayed expiratory cycling and prolonged $t \mathrm{I}$ at all levels of IPAP with the BiPAP. The mean (SD) $t$ I increased significantly (unpaired t-test; $\mathrm{p}<0.01)$ from $1.56(0.51) \mathrm{s}$ to 2.06 $(0.46) \mathrm{s}$. The prolongation of $t \mathrm{I}$ was variable and correlated positively with a change in $V \mathrm{~T} \quad(\mathrm{r}=0.9)$, which increased during some tests. $t \mathrm{I}$ is preset on the Nippy 2 and for nontriggered breaths on the Quantum, and therefore $t \mathrm{I}$ was unchanged with the leak open. The mean $t$ I for the VPAP increased significantly $(\mathrm{p}<0.01)$ from $1.1(0.2) \mathrm{s}$ to $1.61(0.31) \mathrm{s}$ with the leak open, and correlated with the change in the resulting $V \mathrm{~T}(\mathrm{r}=0.75)$.

For the two ventilators that prolonged $t \mathrm{I}$ with the leak open, the delivered $V \mathrm{~T}$ was calculated for the equivalent $t \mathrm{I}$ when the leak was closed. There was a minimal fall in mean (SD) $V$ T of $5.0(19.2) \mathrm{mL}$ with the BiPAP and $2.1(6.8) \mathrm{mL}$ with the VPAP.

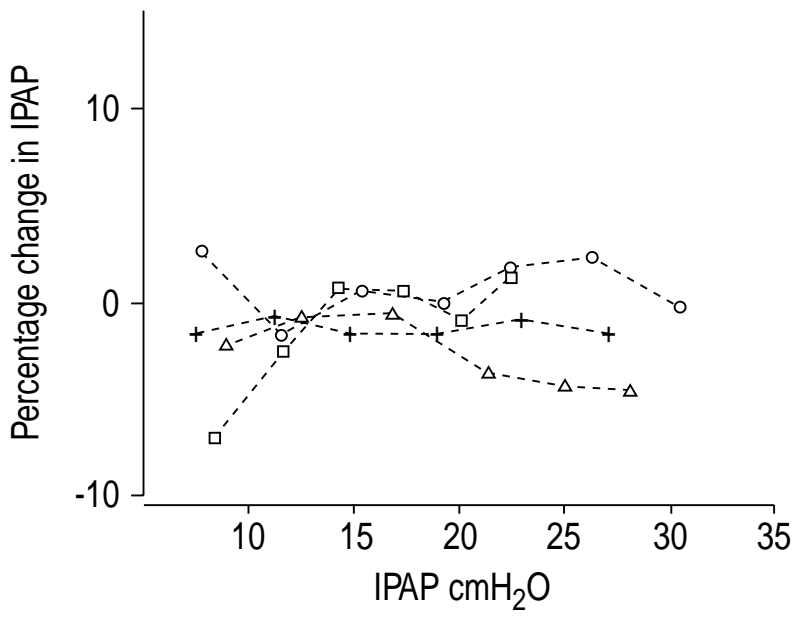

Fig. 3. - The effect on inspiratory positive airway pressure (IPAP) when the leak was opened. $\bigcirc$ : BiPAP ST 30; $\triangle$ : Nippy2; +: Quantum PSV; $\square$ : VPAP II ST.

\section{Trigger sensitivity}

Using one-way analysis of variance (ANOVA) with significance set at $\mathrm{p}<0.05$, there were significant differences between the ventilators with respect to trigger delay times and inspiratory trigger pressure. Post hoc analyses with the Bonferroni test were performed and the results are presented in tables 1 and 2.

The Nippy2 had a significantly longer trigger delay time and larger trigger pressure than other ventilators. The trigger pressures of the BiPAP and VPAP were significantly smaller than the other two ventilators.

\section{Changes in duration and frequency of patient effort}

The mean (SD) $V \mathrm{~T}$ for each ventilator at baseline were: BiPAP 529 (9.6) mL; Nippy2 415 (6.8) mL; Quantum 514 (6.3) mL; and VPAP 457 (4.6) mL. The percentage increases in minute volume from baseline for durations of "patient effort" of 0.25 and $1 \mathrm{~s}$ are shown in figs. 4 and 5. To allow comparison of performance, the "predicted increase" in minute volume illustrated is calculated, assuming that the baseline tidal volume remains constant and that all patient efforts result in a ventilator breath.

With the "patient effort" of $0.25 \mathrm{~s}$ the $t \mathrm{I}$ of the BiPAP was variable with a range of $1.36-2 \mathrm{~s}$ (see also table 3 ). At a rate of 24 breaths $\mathrm{min}^{-1}$ there are only $2.5 \mathrm{~s}$ to complete each respiratory cycle and there was insufficient time for complete expiration when $t$ I was

Table 1. - Mean (SD) trigger delay times with "patient breaths" of 1 second duration, at a rate of $16 \cdot \mathrm{min}^{-1}$

\begin{tabular}{lcccc}
\hline Ventilator & BiPAP ST 30 & Nippy2 & Quantum PSV & VPAP II ST \\
\hline Trigger delay time & $169(33.6)$ & $194(23.9)$ & $155(30.7)$ & $142(27)$ \\
Significance versus VPAP II ST & $\mathrm{p}=0.03$ & $\mathrm{p}<0.01$ & $\mathrm{p}=0.87$ & - \\
Significance versus Quantum PSV & $\mathrm{p}=0.87$ & $\mathrm{p}<0.01$ & - & - \\
Significance versus Nippy2 & $\mathrm{p}=0.04$ & - & - & - \\
\hline
\end{tabular}

Post hoc analysis performed with the Bonferroni test. 
Table 2. - Mean (SD) inspiratory trigger pressures in $\mathrm{cmH}_{2} \mathrm{O}$ with "patient breaths" of 1 second duration at a rate of $16 \cdot \mathrm{min}^{-1}$

\begin{tabular}{lcccc}
\hline Ventilator & BiPAP ST 30 & Nippy2 & Quantum PSV & VPAP II ST \\
\hline Inspiratory trigger pressure & $1.8(0.15)$ & $2.9(0.22)$ & $2.5(0.37)$ & $1.8(0.26)$ \\
Significance versus VPAP II ST & $\mathrm{p}=1$ & $\mathrm{p}<0.01$ & $\mathrm{p}<0.01$ & - \\
Significance versus Quantum PSV & $\mathrm{p}<0.01$ & $\mathrm{p}<0.01$ & - & - \\
Significance versus Nippy2 & $\mathrm{p}<0.01$ & - & - & - \\
\hline
\end{tabular}

Post hoc analysis performed with the Bonferroni test.

prolonged. This caused a fall in expiratory volume, a rise in residual volume and failure of some of the simulated breaths to trigger a ventilator breath. Over the $5 \mathrm{~min}$ period of the test at a rate of 24 breaths $\cdot \mathrm{min}^{-1}$, $28 \%$ of the simulated breaths failed to trigger the BiPAP. Analysing triggered breaths, the mean (SD) EPAP measured at the onset of inspiration was 2.7 (0.69) $\mathrm{cmH}_{2} \mathrm{O}$. The $t \mathrm{E}$ of the preceding breath, defined as the time difference between the start of expiratory flow and the onset of simulated effort was $0.54(0.11) \mathrm{s}$. In comparison, where there was failure to trigger the ventilator, EPAP was $4.0(0.5) \mathrm{cmH}_{2} \mathrm{O}$ and $t$ E was 0.37 $(0.08)$ s. Trigger failure and the reduced $V \mathrm{~T}$ caused by hyperinflation explains the abrupt fall in minute volume seen at the highest rate. With the simulated breaths of $1 \mathrm{~s}$ duration, the expiratory cycling matched $t \mathrm{I}$ to the "patient effort", allowing adequate time for expiration at each $f \mathrm{R}$. There was therefore no hyperinflation or trigger failure and the simulated effort led to a consistent increase in tidal and minute volume at each frequency.

The $T$ I for the Nippy 2 is preset and was therefore unchanged for triggered and timed breaths. There was insufficient time for expiration at the highest $f \mathrm{R}$ leading to hyperinflation and trigger failure with "patient efforts" of both 0.25 and $1 \mathrm{~s}$. With a duration of $0.25 \mathrm{~s}, 26 \%$ of simulated breaths at a $f \mathrm{R}$ of 24 failed to trigger the Nippy2. For triggered breaths, the mean (SD) EPAP measured at the onset of inspiration was 2.8 $(0.18) \mathrm{cmH}_{2} \mathrm{O}$ and $t \mathrm{E}$ was $0.47(0.05) \mathrm{s}$. During episodes of trigger failure the measured EPAP was $3.3(0.19)$

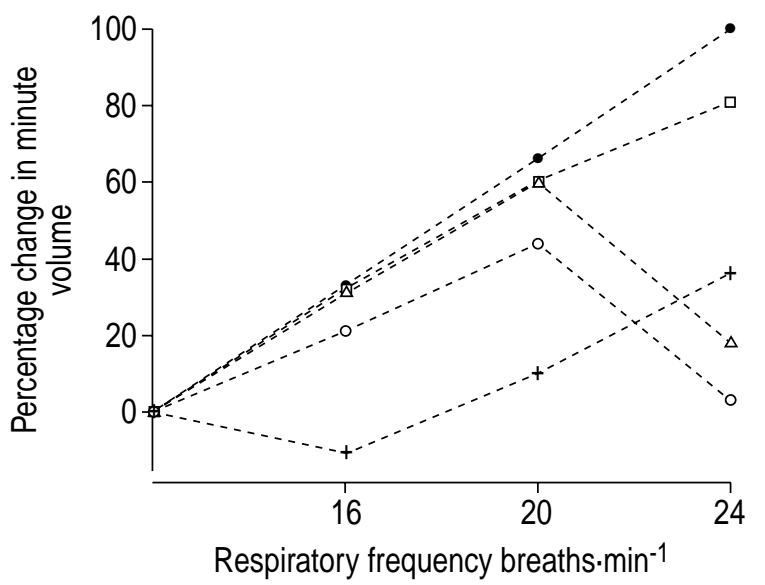

Fig. 4. - The effect of increasing respiratory frequency on minute volume with "patient efforts" of 0.25 seconds. predicted increase; $\bigcirc$ : BiPAP ST 30; $\triangle$ : Nippy2; +: Quantum PSV; $\square$ : VPAP II ST.
$\mathrm{cmH}_{2} \mathrm{O}$ and $t \mathrm{E}$ was $0.37(0.08) \mathrm{s}$. There was $16 \%$ trigger failure with simulated breaths of $1 \mathrm{~s}$ at an $f \mathrm{R}$ of 24 . For triggered breaths EPAP was $3.1(0.42) \mathrm{cmH}_{2} \mathrm{O}$ and $t \mathrm{E}$ was $0.48(0.05) \mathrm{s}$. During episodes of trigger failure EPAP was $3.9(0.56) \mathrm{cmH}_{2} \mathrm{O}$ and $t \mathrm{E}$ was $0.37(0.04) \mathrm{s}$. A consistent rise in tidal and minute volumes was seen with the longer "patient effort" at rates below which trigger failure and hyperinflation occured.

The Quantum produced minute volumes less than "predicted" values during all tests, even though there were no episodes of trigger failure. Cycling from IPAP to EPAP occurs when flow within the ventilator circuit falls to $75 \%$ of the peak flow. With "patient effort" of $0.25 \mathrm{~s}$ and the minimum rise time, this point is reached quickly and results in short ventilator breaths (mean $0.58 \mathrm{~s}$; see table 3 ). The longer "patient effort" duration of $1 \mathrm{~s}$ delayed expiratory cycling and subsequently increased $V$ T. However expiratory cycling still occurs before patient effort is complete and subsequently leads to tidal and minute volumes below the expected values.

Triggered and timed breaths with the VPAP were of very similar duration and volume and thus the increase in minute volume was close to the expected values for "patient efforts" of $0.25 \mathrm{~s}$. $t \mathrm{I}$ was well matched to "patient effort" with simulated efforts of $1 \mathrm{~s}$ and produced the greatest increases in tidal and minute volumes from baseline. There were no episodes of trigger failure.

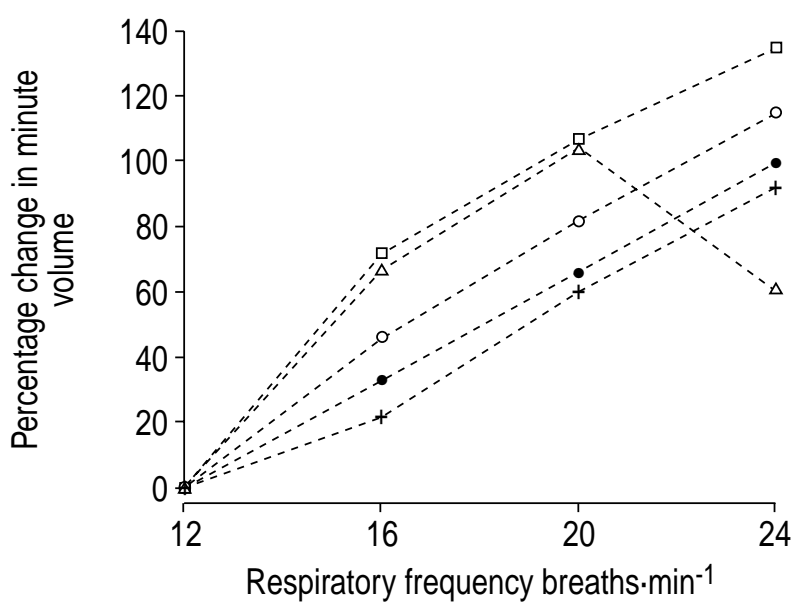

Fig. 5. - The effect of increasing respiratory rate on minute volume with "patient efforts" of 1 second. O: predicted increase; O: BiPAP ST 30; $\triangle$ : Nippy2; +: Quantum PSV: $\square$ : VPAP II ST. 
Table 3. - Mean (SD) ventilator $\hbar$, with varying duration of "patient effort" (PE)

\begin{tabular}{lcc}
\hline Ventilator & $P E=0.25$ seconds & $P E=1$ second \\
\hline BiPAP ST 30 & $1.79(0.15) \mathrm{s}$ & $0.96(0.06) \mathrm{s}$ \\
Nippy2 & $1.93(0.04) \mathrm{s}$ & $1.93(0.03) \mathrm{s}$ \\
Quantum PSV & $0.58(0.07) \mathrm{s}$ & $0.72(0.03) \mathrm{s}$ \\
VPAP II ST & $1(0.06) \mathrm{s}$ & $1.08(0.06) \mathrm{s}$ \\
\hline
\end{tabular}

\section{Discussion}

The results of these bench assessments show that there are a number of dynamic changes in the behaviour of the ventilators in response to leaks and variations in imposed effort. Many of these changes cannot be predicted from prior knowledge of each ventilator's quoted performance characteristics.

The potential deterioration in $V \mathrm{~T}$ delivered by the ventilator during an air leak may lead to ineffective ventilation and subsequent arterial desaturation during NIPPV [14]. This reduction in effective ventilation is theoretically minimised by the use of pressure-preset devices and the fall in $V$ T seen with the machines tested on the lung model was minimal in the face of a persistent leak. The effects of air leakage during NIPPV can be more complex than a fall in IPAP and $V$ T, and the changes in $t$ I seen with the BiPAP and the VPAP are examples of this. The prolongation of $t \mathrm{I}$ leads to an unpredicted and unnecessary increase in $V \mathrm{~T}$ of up to $15 \%$ that may potentially be detrimental.

As illustrated with the lung model, prolongation of $t \mathrm{I}$ when the patient's $f \mathrm{R}$ is high may lead to insufficient time for expiration, hyperinflation and trigger failure. It would therefore seem to be a disadvantage to prolong $t \mathrm{I}$ during an air leak at a high $f \mathrm{R}$. Leaks and subsequent prolongation of $t$ I while using the BiPAP can increase the number of arousals during light sleep and contribute to sleep fragmentation [15].

Failure to trigger the ventilator with subsequent wasted patient effort in up to $40 \%$ of breaths during pressure support ventilation has been shown to occur in $54-75 \%$ of stable intubated patients weaning from invasive ventilation $[16,17]$. The prevalence of such trigger failures during NIPPV is not known, but significant differences in the sensitivity of triggering of the four ventilators have been demonstrated. The maximum difference in trigger delay was $52 \mathrm{~ms}$ and in trigger pressure was $1.1 \mathrm{cmH}_{2} \mathrm{O}$. The differences demonstrated represent an increase in work done by the patient that will be repeated during each triggered breath, and may be of particular importance in a breathless, tiring patient [12].

Cycling to expiration before the patient's inspiratory effort is complete leads to an increase in the inspiratory load imposed, whilst prolongation of inspiratory pressure beyond the duration of inspiratory effort made by the patient can lead to active expiration and an increase in the expiratory work [18]. Under the specific test conditions employed, the Quantum cycled prematurely to expiration. The ventilator $t \mathrm{I}$ is shorter when inspiration is terminated by flow falling to a higher fixed percentage of the peak value [13]. In stable intubated patients on pressure support ventilation, ventilator $t$ I was significantly shorter when inspiration was terminated at $50 \%$ of peak flow compared with $25 \%$ [19]. However, there was no significant effect on $V \mathrm{~T}, f \mathrm{R}$, or IPAP delivered, and a higher percentage such as that employed on the Quantum $(75 \%)$ was not examined.

Cycling to expiration with the Nippy2 is dependent solely on the $t$ I selected by the operator and the trigger failures that were observed at the highest rate on the lung model would have been avoided by the selection of a shorter $t$ I. The BiPAP and the VPAP cycle to expiration according to unquoted flow criteria, which matched $t \mathrm{I}$ efficiently to a "patient effort" of $1 \mathrm{~s}$, allowing adequate time for expiration even at the highest $f$ R. However, as was demonstrated on an earlier model of the BiPAP [5], $t$ I lengthens if patient effort is less than $0.5 \mathrm{~s}$ in duration, which may occur at particularly high $f \mathrm{R}[16]$.

NIPPV can reduce measured inspiratory effort during the treatment of acute and chronic respiratory failure [9, 20], and during exercise [21] when the ventilatory demands of the patient are particularly high. However the response of the ventilator to an increase in inspiratory effort made by the patient has been little explored. Using simulated patient breaths on a lung model, changes in the inspiratory flow demand have been shown to alter a number of measured parameters [13]. There were differences between the devices tested, but in general, increasing the ventilatory demand led to an increase in the peak flow delivered by the ventilator, but also increased the expiratory loading and reduced the sensitivity of the triggering. The degree to which this affected the actual ventilation delivered was not quantified.

This study found considerable differences in ventilation delivered by different ventilators using the same test conditions. At an equivalent IPAP of $20 \mathrm{cmH}_{2} \mathrm{O}$ there was a difference of up to $115 \mathrm{~mL}$ in the $V \mathrm{~T}$ delivered by the four ventilators. Similar differences have been illustrated in previous comparisons during bench testing $[5,12]$ and in patients with stable chronic respiratory failure [3]. It has previously been argued that this difference in $V \mathrm{~T}$ delivered for a given peak IPAP is mainly due to the pressure waveform of the ventilator and that this needs to be considered in the selection of a machine for NIPPV [5].

With the introduction of simulated patient effort, further differences between the ventilation delivered by each of the ventilators become apparent. When a brief inspiratory effort is made by the simulated patient there may be a fall in $V \mathrm{~T}$ and indeed a fall in minute volume, despite an increase in $f \mathrm{R}$. For some of the ventilators there is a marked increase in tidal and minute volumes with a more prolonged patient effort over and above that expected by an increase in $f \mathrm{R}$ alone. At a high $f \mathrm{R}$, there may be a drop in minute ventilation caused by trigger failures and hyperinflation. Variable respiratory frequencies and durations of respiratory effort would be expected in breathless patients with ventilatory failure. The unpredictable response of these ventilators under these circumstances has not previously been demonstrated.

There are limitations in applying the findings of a lung model study to the clinical situation. Any leaks, 
and the duration and degree of patient effort, will vary during each breath. In addition, the effect of airways resistance on the ventilation delivered has not been considered. In particular the glottis behaves as a variable resistance during noninvasive intermittent positive pressure ventilation, affecting the pressure waveform and tidal volume independent of inspiratory effort [22]. However, we have illustrated differences in the responsiveness of apparently similar bilevel ventilators currently in use for noninvasive intermittent positive pressure ventilation. The importance of these differences will depend on the precise clinical situation, but may be sufficient to influence the choice of ventilator. These differences may be most significant when selecting a ventilator for the treatment of breathless patients with ventilatory failure.

\section{References}

1. Ellis ER, Bye PTP, Bruderer JW, Sullivan CE. Treatment of respiratory failure during sleep in patients with neuromuscular disease. Am Rev Respir Dis 1987; 135: $148-152$.

2. Carroll N, Branthwaite MA. Control of nocturnal hypoventilation by nasal intermittent positive pressure ventilation. Thorax 1988; 43: 349-353.

3. Meecham Jones DJ, Wedzicha JA. Comparison of pressure and volume preset nasal ventilator systems in stable chronic respiratory failure. Eur Respir J 1993; 6: $1060-1064$

4. Elliott MW, Aquilina R, Green M, Moxham J, Simonds AK. A comparison of different modes of non-invasive ventilatory support: effects on ventilation and inspiratory muscle effort. Anaesthesia 1994; 49: $279-283$.

5. Smith IE, Shneerson JM. A laboratory comparison of four positive pressure ventilators used in the home. Eur Respir J 1996; 9: 2410-2415.

6. Bach JR, Alba AS. Management of chronic alveolar hypoventilation by nasal ventilator. Chest 1990; 97: 52-57.

7. Younes M. Proportional assist ventilation and pressure support ventilation: similarities and differences. Intensive Care Emerg Med 1991; 15: 361 - 380.

8. Smith TC, Marini JJ. Impact of peep on lung mechanics and work of breathing in severe airflow obstruction. J Appl Physiol 1988; 65: 1488-1499.

9. Nava S, Ambrosino N, Rubini F, et al. Effect of nasal pressure support ventilation and external peep on diaphragmatic activity in patients with severe stable COPD. Chest 1993; 103: $143-150$.
10. Shivaram U, Cash ME, Beal A. Nasal continuous positive airway pressure in decompensated hypercapnic respiratory failure as a complication of sleep apnea. Chest 1993; 104: 770-774.

11. Nava S, Ambrosino N, Bruschi C, Confalonieri M, Rampulla C. Physiological effects of flow and pressure triggering during non-invasive mechanical ventilation in patients with chronic obstructive pulmonary disease. Thorax 1997; 52: 249-254.

12. Lofaso F, Brochard L, Hang T, Lorino H, Harf A, Isabey D. Home versus intensive care pressure support devices: experimental and clinical comparison. $\mathrm{Am}$ J Respir Crit Care Med 1996; 153: 1591-1599.

13. Bunburaphong $\mathrm{T}$, Imanaka $\mathrm{H}$, Nishimura M, Hess D, Kacmarek RM. Performance characteristics of bilevel pressure ventilators. Chest 1997; 111: $1050-1060$.

14. Bach JR, Robert D, Leger P, Langevin B. Sleep fragmentation in kyphoscoliotic individuals with alveolar hypoventilation treated by NIPPV. Chest 1995; 107: $1552-1558$.

15. Meyer TJ, Pressman MR, Benditt J, et al. Air leaking through the mouth during nocturnal nasal ventilation: effect on sleep quality. Sleep 1997; 20: $561-569$.

16. Fabry B, Guttman J, Eberhard L, Bauer T, Haberthur C, Wolff G. An analysis of desynchronization between the spontaneously breathing patient and ventilator during inspiratory pressure support. Chest 1995; 107 : $1387-1394$.

17. Nava S, Bruschi C, Fracchia C, Braschi A, Rubini F. Patient-ventilator interaction and inspiratory effort during pressure support ventilation in patients with different pathologies. Eur Respir J 1997; 10: 177-183.

18. Jubran A, Van De Graaf B, Tobin MJ. Variability of patient-ventilator interaction with pressure support ventilation in patients with chronic obstructive pulmonary disease. Am J Respir Crit Care Med 1995; 152: $129-136$.

19. MacIntyre NR, Ho LI. Effects of initial flow rate and breath termination criteria on pressure support ventilation. Chest 1991; 99: 134-138.

20. Carrey Z, Gottfried SB, Levy RD. Ventilatory muscle support in respiratory failure with nasal positive pressure ventilation. Chest 1995; 107: $1387-1394$.

21. Maltais F, Reissman H, Gottfried SB. Pressure support reduces inspiratory effort and dyspnea during exercise in chronic airflow obstruction. $\mathrm{Am}$ J Respir Crit Care Med 1995; 151: $1027-1033$.

22. Jounieaux V, Parreira VF, Delguste P, Aubert G, Rodenstein DO. Nasal mask pressure waveform and inspiratory muscle rest during nasal assisted ventilation. Am J Respir Crit Care Med 1997; 155: 2096-2101. 